\title{
Mans Akerman, Henryk A. Domanski, Kjell Jonsson: Fine needle aspiration of bone tumors
}

\author{
Swante R. Orell (Ed.): The clinical, radiological, cytological approach: monographs in \\ clinical cytology, Karger AG Basel, volume 19-XII +92 p, 88 figures, 61 in color, 10 \\ tables, hard cover, 2010, CHF 132,00/EUR 94,50/USD 132,00, ISBN 978-3-8055-9214-7, \\ e-ISBN 978-3-8055-9215-4
}

\section{Pierre Kehr}

Received: 1 May 2010/Accepted: 5 May 2010/Published online: 16 May 2010

(C) Springer-Verlag 2010

This manual is the 19th volume of a series untitled: "Monographs in Clinical Cytology", edited by S. R. Orell. The purpose of this book is to facilitate the cytological evaluation of Fine Needle Aspiration Biopsies from skeletal lesions and to provide diagnostic criteria based on the combined evaluation of clinical data and radiographic and cytological features. The major aim is to thoroughly describe and illustrate the most common entities as well as the diagnostic use of ancillary techniques. A number of rare primary bone tumors are also illustrated.

The selection of entities illustrated in this comprehensive manual is based mainly on experience with patients referred to the Musculoskeletal Center in Lund, Sweden, which comprises biopsy data from approximately 1,000 tumors collected between 1966 and 2006.
The manual is divided into 14 chapters that cover most of the bone tumors and lesions: osteogenic tumors, cartilaginous tumors, Ewing family tumors, Notochordal tumors, Giant cell lesions, benign Osteoclast lesions, Lymphohaematopoetic and Histiocytic tumors, inflammatory lesions, bone metastases. Imaging illustrations and histological cuts are numerous and outstandingly presented.

This publication will be a valuable resource for pathologists, cytopathologists, radiologists, oncologists, but also orthopedic surgeons involved in the work-up and management of patients with bone lesions.

Dr. Claude Karger Strasbourg

No funds were received in support of this study.
P. Kehr $(\bowtie)$

SOTEST, Strasbourg, France

e-mail: kehrpier@aol.com 